Research Article

\title{
Synthesis of Ash Derived Co/Zeolite Catalyst for Hydrogen Rich Syngas Production via Partial Oxidation of Methane
}

\author{
A. Zaffar', B.A. Khan², A.H. Khoja ${ }^{3, *}$, U.M. Khan ${ }^{3}$, Q. Sarmad ${ }^{3}$, M.T. Mehran', \\ Salman Raza Naqvi ${ }^{1}$, Majid Ali $^{3}$
}

${ }^{1}$ School of Chemical and Materials Engineering (SCME), National University of Sciences \& Technology (NUST), Sector H-12 Islamabad (44000), Pakistan.

2Department of Applied Science and Technology, Politecnico di Torino, Corso Duca degli Abruzzi, 24, 10129 Torino, Italy.

${ }^{3}$ U.S.-Pakistan Centre for Advanced Studies in Energy (USPCAS-E), National University of Sciences \&

Technology (NUST), Sector H-12 Islamabad (44000), Pakistan.

Received: 15 $5^{\text {th }}$ March 2021; Revised: 30th April 2021; Accepted: $5^{\text {th }}$ May 2021

Available online: 10 ${ }^{\text {th }}$ May 2021; Published regularly: September 2021

Abstract

The objective of this study was to analyze the catalytic performance of series of cobalt-modified Zeolite-4A supported catalysts for the syngas $\left(\mathrm{CO}\right.$ and $\left.\mathrm{H}_{2}\right)$ production at $800{ }^{\circ} \mathrm{C}$ via the partial oxidation of methane (POM). The Co/Zeolite-4A catalyst was synthesized using a two-step hydrothermal method from coal fly ash. The synthesized catalysts were characterized by X-ray Diffraction (XRD), Scanning Electron Microscope (SEM), Energy Dispersive X-ray (EDX), and Thermogravimetric Analysis (TGA). The catalyst shows a crystalline structure with stability up to $900{ }^{\circ} \mathrm{C}$. The catalytic performance analysis shows the $\mathrm{CH}_{4}$ conversion increases from 29 to $68 \%$ for 0 and 10 wt\% Co over Zeolite-4A, respectively. The $\mathrm{H}_{2}$ selectivity was improved from $28-56 \%$, while $\mathrm{CO}$ selectivity increased from $24-52 \%$ making $\mathrm{H}_{2} / \mathrm{CO}$ ratio $>1$. The stability analysis shows the $10 \% \mathrm{Co} /$ Zeolite $-4 \mathrm{~A}$ withstand for $24 \mathrm{~h}$ a time on stream (TOS). Finally, the spent catalyst analysis was carried out to check the carbon formation along with its structural analysis. The minimal carbon formation is analyzed in $24 \mathrm{~h}$ TOS for POM reaction.

Copyright (C 2021 by Authors, Published by BCREC Group. This is an open access article under the CC BY-SA License (https://creativecommons.org/licenses/by-sa/4.0).

Keywords: Partial oxidation of Methane (POM); Zeolite-4A; Hydrogen production; Syngas

How to Cite: A. Zaffar, B.A. Khan, A.H. Khoja, U.M. Khan, Q. Sarmad, M.T. Mehan, S.R. Naqvi, M. Ali (2021). Synthesis of Ash Derived Co/Zeolite Catalyst for Hydrogen Rich Syngas Production via Partial Oxidation of Methane. Bulletin of Chemical Reaction Engineering \& Catalysis, 16(3), 507-516 (doi:10.9767/bcrec.16.3.10614.507516)

Permalink/DOI: https://doi.org/10.9767/bcrec.16.3.10614.507-516

\section{Introduction}

Since the discovery of the ill effects of greenhouse gases (GHGs), the emphasis of the scientific community has been to mitigate those ef-

\footnotetext{
* Corresponding Author.

Email: asif@uspcase.nust.edu.pk (A.H. Khoja);

Telp.: +92-51-8865343
}

fects and transition towards zero emission fuels. Hydrogen, due to its high energy density and renewability, has been the major focus [1,2]. However, the renewable hydrogen production still needs to grow exponentially to meet the energy demands of the world. Therefore, there is a need of transition techniques to produce hydrogen from fossil fuels to consume them in an environ- 
mentally friendly way with minimum GHG emissions [3-6].

Obtaining valuable chemical products from $\mathrm{CH}_{4}$ has been studied extensively [7-10]. Commonly, this is achieved by obtaining syngas from $\mathrm{CH}_{4}[3,11,12]$. The main component of natural gas is $\mathrm{CH}_{4}$ which itself is a GHG but can be used in green energy applications which have been a focus of researchers owing to their high efficiency and low emissions [13-16]. The $\mathrm{CH}_{4}$ is usually converted to syngas using steam methane reforming [17], dry reforming [18-20], and partial oxidation of methane (POM) [4,21$23]$. Both the reforming processes are very endothermic, i.e. high temperature and/or high pressure of $\mathrm{CH}_{4}$ is required, whereas none of these are required for POM to syngas as it is an exothermic process [4,24]. Moreover, POM yields a hydrogen to carbon monoxide ratio of $>1$ which is ideal for Fischer-Tropsch synthesis for liquid fuel production [9,22,25].

A vast number of catalysts have been studied and proposed for POM to syngas [3,4,21,24, 26-28]. Kobayashi et al. [27] used Rh/zeolite catalyst and were able to obtain conversion of $84 \%$ with a $\mathrm{H}_{2} / \mathrm{CO}$ ratio of 2.0 at $600{ }^{\circ} \mathrm{C}$ and the catalytic performance further improved with the addition of cobalt [28]. Using of cobalt as catalyst with $\mathrm{Co}_{3} \mathrm{O}_{4}$ as the key active phase is usually considered a less expensive and practical substitute to costly noble-metal based catalysts which possess a higher activity [29]. Cobalt excellent catalytic activity is attributed to its good redox properties, especially, the ease with which cobalt ions can switch between their oxidation states of +2 and +3 allowing the lattice oxygen to move easily [2,30,31].

To enhance the catalytic activity of cobalt, the most used strategy is to disperse it over a porous support, increasing the available surface area for the reaction to take place $[1,26,32]$. Usually this results in $\mathrm{Co}_{3} \mathrm{O}_{4}$ having small crystallite size and high specific area, but it can result in strong cobalt-support interactions which can negatively affect the redox properties of cobalt $[33,34]$. This problem can be dealt with by using zeolite supports which has capability to improve the Co dispersion and provide more active sites [21]. Zeolite can be easily synthesized from a waste coal fly ash. Fly ash is another waste material which is difficult to handle in coal fired power plants [31].

In this study, zeolite-4A was synthesized from coal fly ash using two step hydrothermal reaction. The prepared zeolite was then impregnated with different Co loadings and was analyzed using X-ray Diffraction (XRD), Scanning Electron Microscope (SEM), Energy Dis- persive X-ray (EDX), and Thermogravimetric Analysis (TGA). The catalytic activity tests of all the samples were performed. The stability test of the best performing catalyst was carried out for $24 \mathrm{~h}$. The spent catalysts were analyzed using SEM and TGA analysis for carbon formation analysis.

\section{Materials and Methods}

\subsection{Synthesis of Zeolite-4A from Coal Fly Ash}

Coal fly ash which had been obtained from local coal plant is a waste and is very hazardous to environment, therefore, converting the fly ash into other useful products is very advantageous. Zeolite-4A preparation from fly ash is quite easy as the fly ash consists of compounds, which are main constituents of Z- 4A [35]. Zeolite-4A was prepared by 2 step hydrothermal treatment method [26]. First the collected fly ash was dried, crushed, and after sieving it from a screen of $0.2 \mathrm{~mm}, 30 \mathrm{~g}$ of fly ash was introduced into $5 \mathrm{M} \mathrm{NaOH}$ solution (ACS reagent) in $700 \mathrm{~mL}$ beaker. The temperature for the dissolution was kept at $100{ }^{\circ} \mathrm{C}$ for 2 $\mathrm{h}$ with nonstop stirring at $300 \mathrm{RPM}$ using magnetic stirrer. Filtration process was then carried out to obtain a clear solution. The molar ratio of the synthesized mixture was adjusted as $\mathrm{SiO}_{2} / \mathrm{Al}_{2} \mathrm{O}_{3} \approx 1, \quad \mathrm{Na}_{2} \mathrm{O} / \mathrm{SiO}_{2}$ 1-2, and $\mathrm{H}_{2} \mathrm{O} / \mathrm{Na}_{2} \mathrm{O} \approx 40$ for the synthesis of single phase and pure Z-4A [36]. A mixed solution was prepared to attain this ratio; therefore, $200 \mathrm{~mL}$ of aluminate solution (5 M NaOH solution and $3 \mathrm{~g}$ of $\mathrm{Al}$ powder) was added to clear filtrate Fly ash solution. Then this solution was stirred for 30 minutes at room temperature at 500 RPM. Primary gel was prepared by aging solution for $12 \mathrm{~h}$ overnight. After this the solution was filtered and filtrate were kept in Teflon autoclaves (heat resistant templates) and placed in oven for 1.5 hour for $90{ }^{\circ} \mathrm{C}$ and then for $2 \mathrm{~h}$ at $95{ }^{\circ} \mathrm{C}$. After that solution was cooled for $12 \mathrm{~h}$ at room temperature and then it was again filtered. The obtained residue on filter paper was dried in oven as the dried product is Zeolite-4A. The dried sample was then calcined at $900{ }^{\circ} \mathrm{C}$. After preparation, characterization, and analysis of its various properties, Zeolite$4 \mathrm{~A}$ was incorporated as a catalyst support. Figure 1 shows the schematic route used for the synthesis of Zeolite-4A.

\subsection{Synthesis of Co/Zeolite-4A Catalyst}

The 5 wt\% solution of cobalt was prepared by dissolving cobalt(II) nitrate hexahydrate $\left(\mathrm{Co}\left(\mathrm{NO}_{3}\right)_{2} .6 \mathrm{H}_{2} \mathrm{O}\right)$ (Sigma Aldrich, 99.99\% pure) 
precursor salt in DI water. Then Zeolite-4A was added to the solution and stirred for 15 minutes at $60{ }^{\circ} \mathrm{C}$. After stirring, the samples were washed with distilled water and were dried overnight at $110{ }^{\circ} \mathrm{C}$ in oven. Same process was repeated with $2.5,7.5$, and 10 weight percent cobalt loadings. Before usage of prepared catalyst for syngas production they were calcined at various temperature of $500,600,700$, and $800{ }^{\circ} \mathrm{C}$ for $4 \mathrm{~h}$. Figure 2 shows the synthesis route used for the preparation of $\mathrm{Co} /$ Zeolite$4 \mathrm{~A}$ catalyst preparation.

\subsection{Catalyst Characterization}

The crystallinity and structure of the fresh catalyst was determined with X-Ray diffraction (XRD) using D-8 Advance (Bruker, Germany) with exciting wavelength of $\mathrm{Cu}-\mathrm{K} \alpha$ radiation $(\lambda$ $=0.15418 \mathrm{~nm}$ ). The scan rate was set at $0.2^{\circ} \mathrm{s}^{-1}$ for $2 \theta=10^{\circ}$ to $80^{\circ}$. JEOL scanning electron microscope (SEM) (Japan, JSM 6490-A) was used for surface morphological analysis of the prepared Zeolite-4A support and was also used for the determination of the surface morphology of

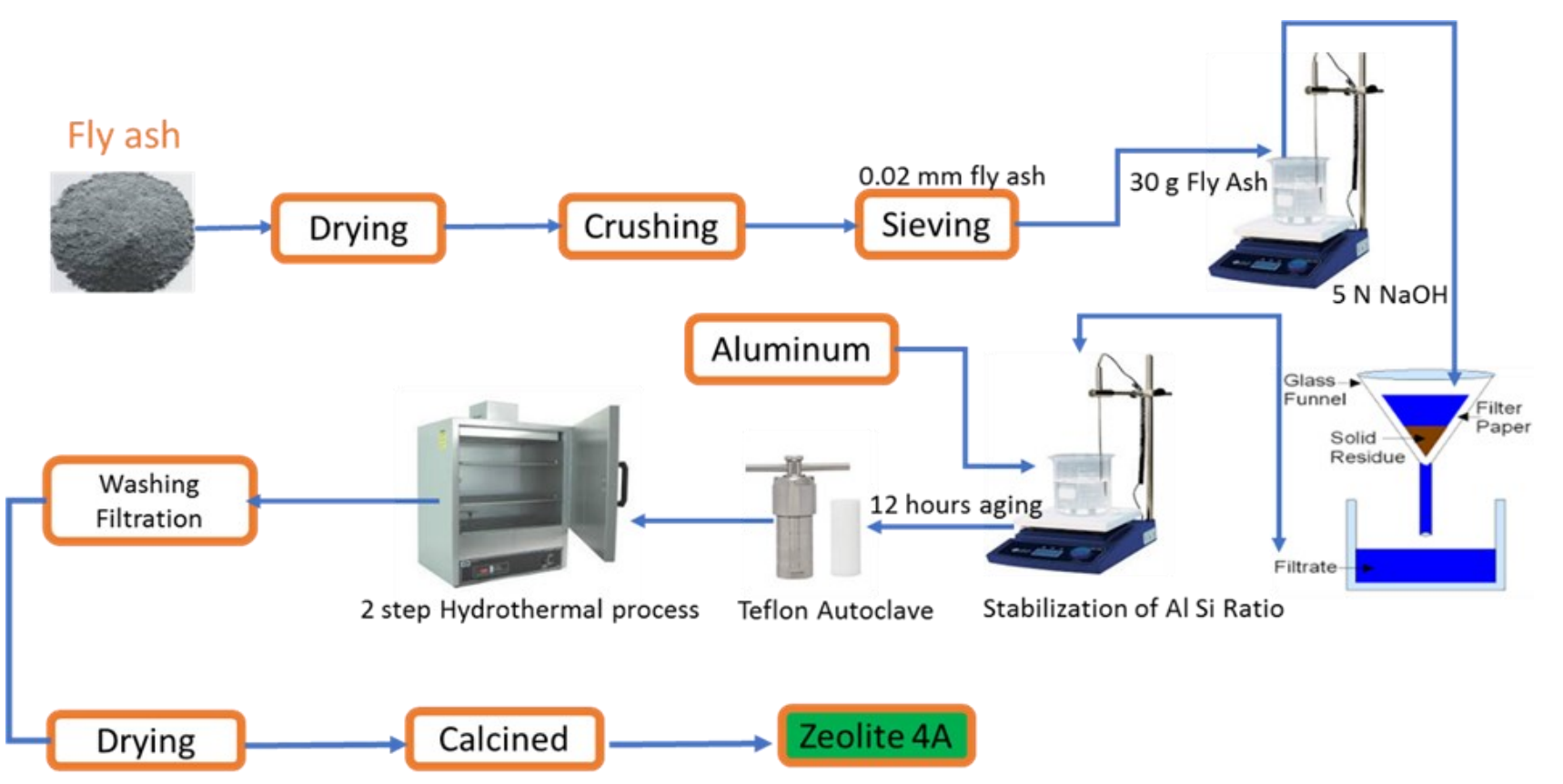

Figure 1. Schematic of Zeolite-4A synthesis via two step hydrothermal process from coal fly ash.

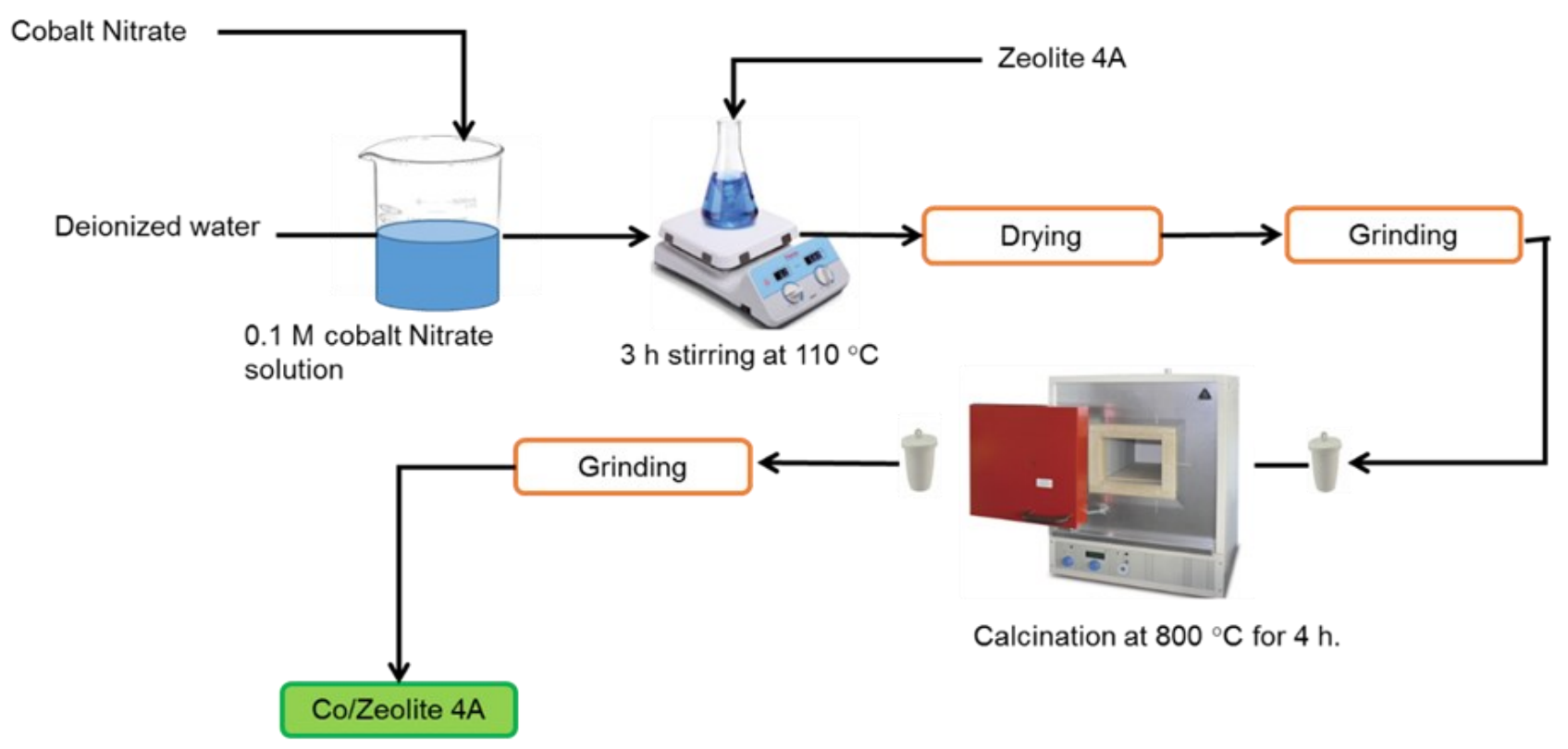

Figure 2. Synthesis of Co/Zeolite-4A. 
the prepared Co based catalyst. The sample was gold coated before use for the analysis of SEM/EDX.

Thermal analysis was performed by (TA instruments USA) TGA Thermal Gravimetric analyzer. Samples were heated from $25^{\circ} \mathrm{C}$ to 900 ${ }^{\circ} \mathrm{C}$ with a heating rate of $10^{\circ} \mathrm{C} /$ min under $\mathrm{N}_{2}$ flowrate of $50 \mathrm{~mL} \cdot \mathrm{min}^{-1}$ [37]. The product gases of POM were analyzed with Gas Chromatography (GC-2010 Pro, SHIMADZU Japan) equipped with a TCD column (RT-MS5A) capable of detecting $\mathrm{H}_{2}, \mathrm{CO}, \mathrm{CO}_{2}$, and $\mathrm{CH}_{4}$.

\subsection{Experimental Setup for Partial Oxidation of} Methane (POM)

Figure 3 shows the schematic of the experimental setup used to carry out POM reaction. The prepared cobalt loaded catalyst with varying amount of cobalt were mounted into, Parr Inc. (USA) fixed bed reactor. $\mathrm{CH}_{4}$ and $\mathrm{O}_{2}$ were introduced into the reactor with a ratio of 2:1. A thermocouple was associated with power controller to control the temperature of reactor. The rector was made of SS-316 having an inner diameter of $1 / 2$ inch. The prepared catalysts were sandwiched between quartz wool and inserted into the center of the rector. The product were analyzed on Gas Chromatography (GC Shimadzu 2010) using TCD column [31].
2.5 Catalytic Activity Performance Calculations

The catalytic performance of Co/Zeolite- $4 \mathrm{~A}$ for POM was visualized by calculating $\mathrm{CH}_{4}$ conversion, $\mathrm{H}_{2}$ selectivity, $\mathrm{CO}$ selectivity, and $\mathrm{H}_{2} / \mathrm{CO}$ ratio. $\mathrm{CH}_{4}$ conversion, $\mathrm{H}_{2}$ selectivity, $\mathrm{CO}$ selectivity, and $\mathrm{H}_{2} / \mathrm{CO}$ ratio were calculated using Eqs. 1-4.

$$
\begin{aligned}
& \mathrm{CH}_{4} \text { conversion }\left(\mathrm{X}_{\mathrm{CH}_{4}}\right) \%=\frac{\mathrm{CH}_{4, \text { in }}-\mathrm{CH}_{4, \text { out }}}{\mathrm{CH}_{4}} \times 100 \% \\
& \mathrm{H}_{2} \text { selectivity }\left(\mathrm{S}_{\mathrm{H}_{2}}\right) \%=\frac{\left(n \mathrm{H}_{2}\right)_{\text {produced }}}{\left(2 \times n C \mathrm{H}_{4}\right)_{\text {converted }}} \times 100 \% \\
& \mathrm{CO} \text { Selectivity }\left(\mathrm{S}_{\mathrm{CO}}\right) \%=\frac{(n \mathrm{CO})_{\text {produced }}}{\left(n C \mathrm{CH}_{4}\right)_{\text {converted }}} \times 100 \% \\
& \mathrm{H}_{2} / \mathrm{CO} \text { ratio }=\frac{\left(n \mathrm{H}_{2}\right)_{\text {produced }}}{(n \mathrm{CO})_{\text {produced }}}
\end{aligned}
$$

\section{Results and Discussion}

\subsection{Physicochemical Properties of Catalyst}

Figure 4 shows the XRD spectra obtained for Zeolite and Co/Zeolite-4A. Zeolite-4A was matched with JCPDS card \#39-0222 while $\mathrm{Co}_{2} \mathrm{O}_{3}$ was matched with JCPDS card $\# 42-1467$. The cobalt oxide that formed as a result of impregnation was found to possess cu-

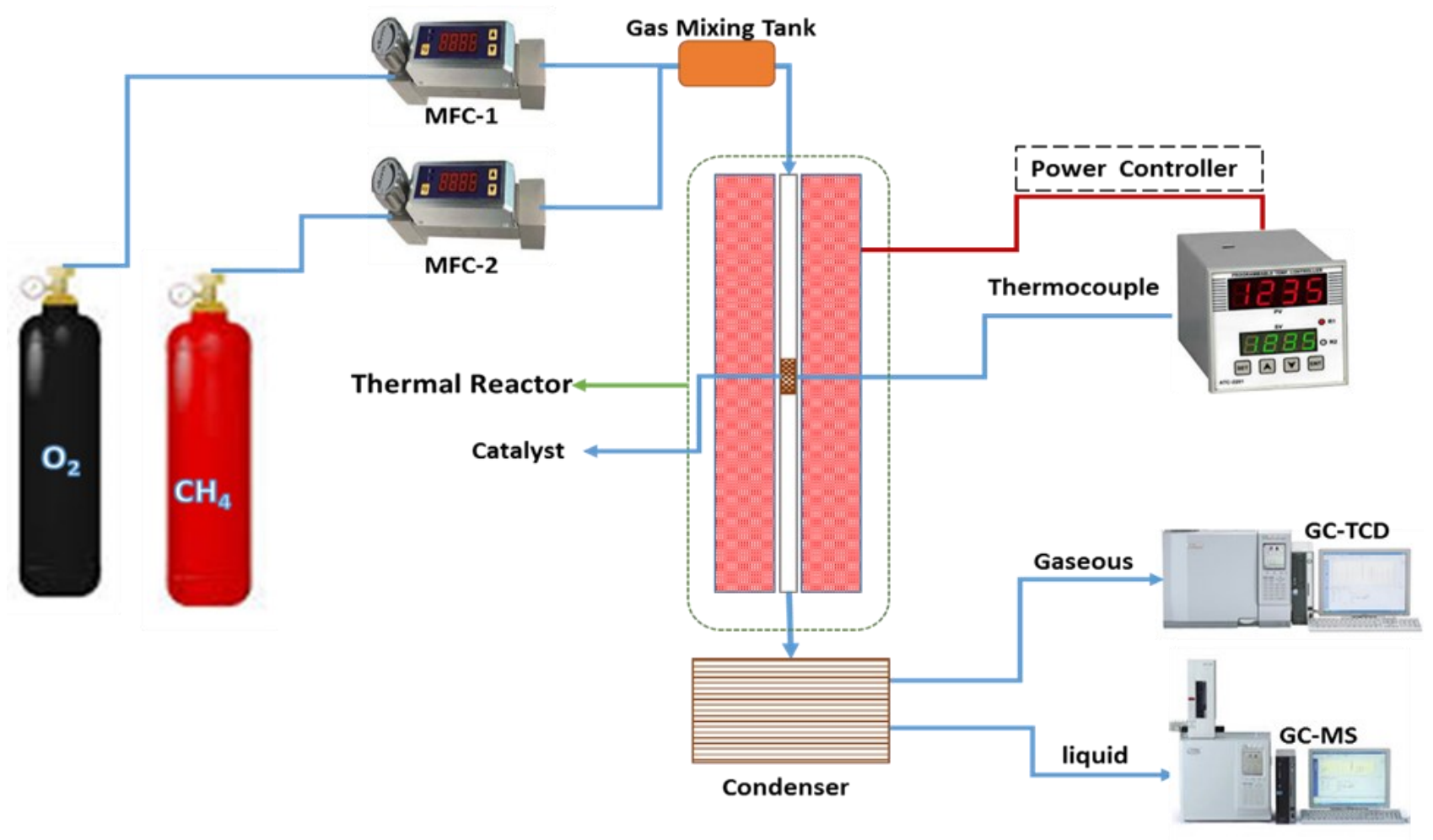

Figure 3. Experimental setup for catalytic partial oxidation of methane. 
bic crystalline structure possessing the Fm3c space group. Figure 5 shows the SEM micrographs of Zeolite-4A and Co/Zeolite- $4 \mathrm{~A}$ at a magnification of $1 \mu \mathrm{m}$. It can be seen from the images that the zeolite itself possesses a flaky structure. Figure 5 (b) shows the SEM images

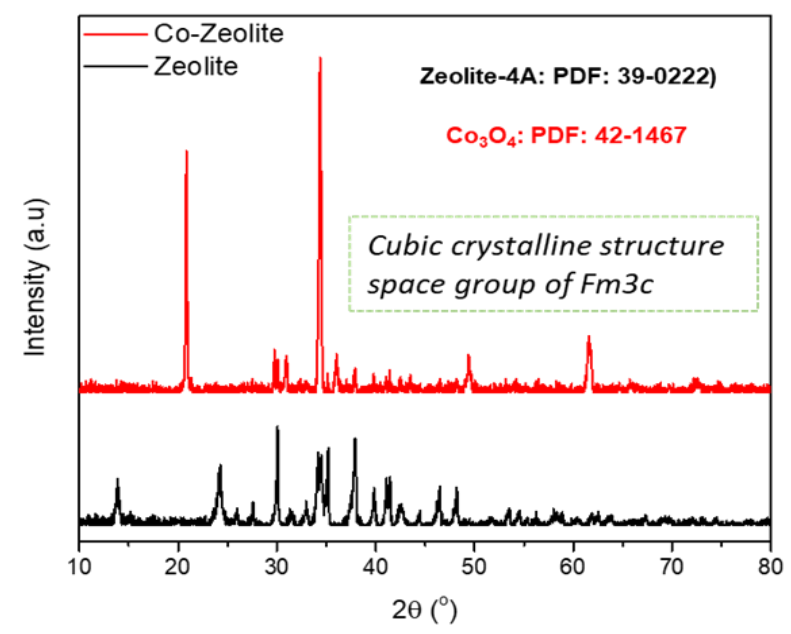

Figure 4. XRD analysis of Zeolite- $4 \mathrm{~A}$ and Co/Zeolite-4A.
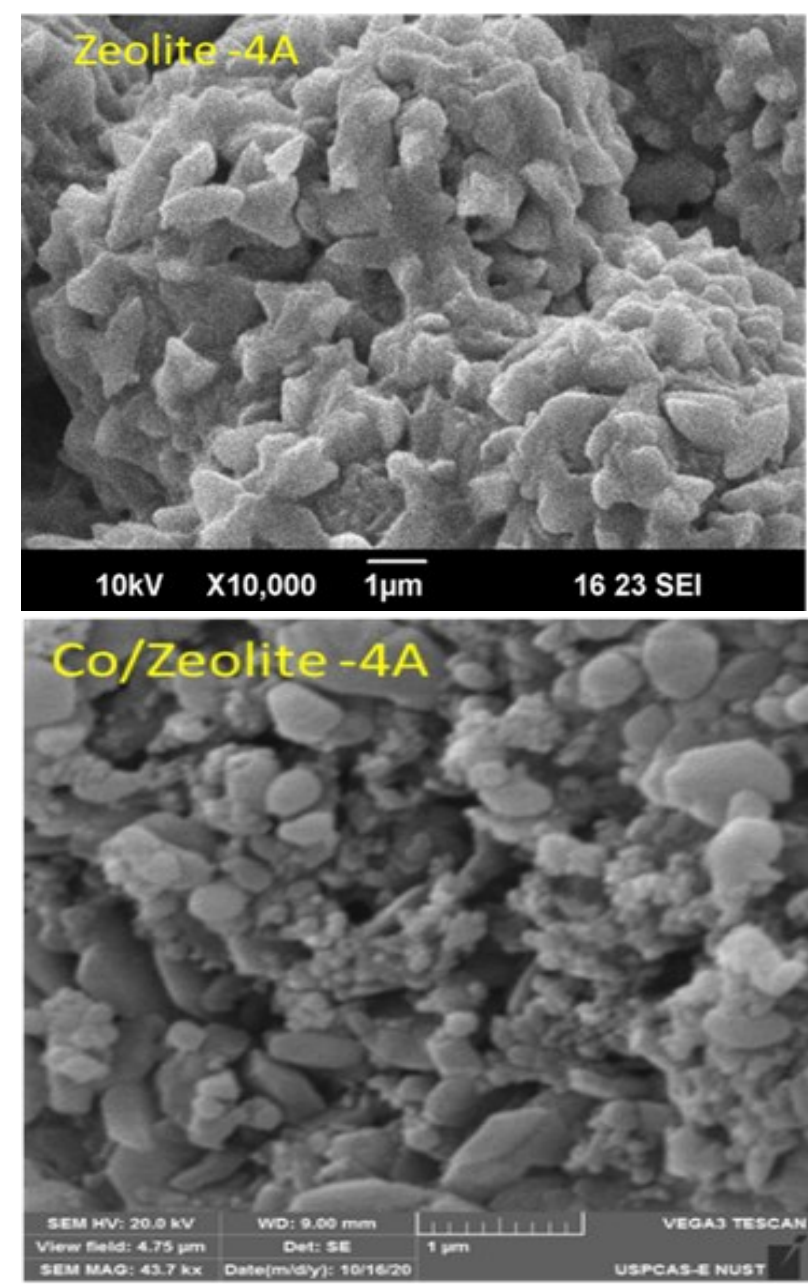

Figure 5. SEM Micrographs (a) Zeolite-4A (b) Co/Zeolite-4A. of Zeolite-4A after impregnation with cobalt. The flake structure of Zeolite-4A can be seen and possibly the cobalt particles are dispersed over the surface. Figure 6 shows the EDX results of Co/Zeolite-4A. Since the precursor of Zeolite-4A, coal fly ash, consists of multiple metal oxides which got incorporated in the structure of Zeolite-4A, can be seen. The EDX results are in line with the XRD results and show that Co/Zeolite-4A was obtained, where we can see the presence of possible elements in the provided composition including cobalt.

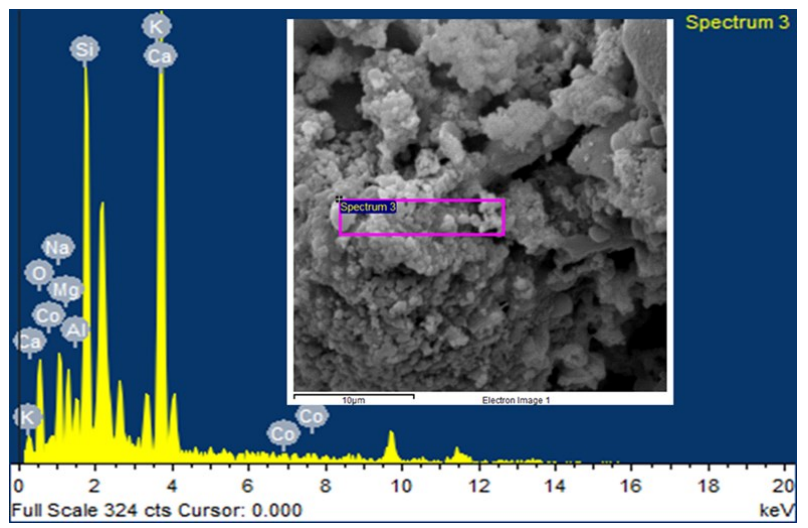

Figure 6. EDX analysis of Co/Zeolite-4A.

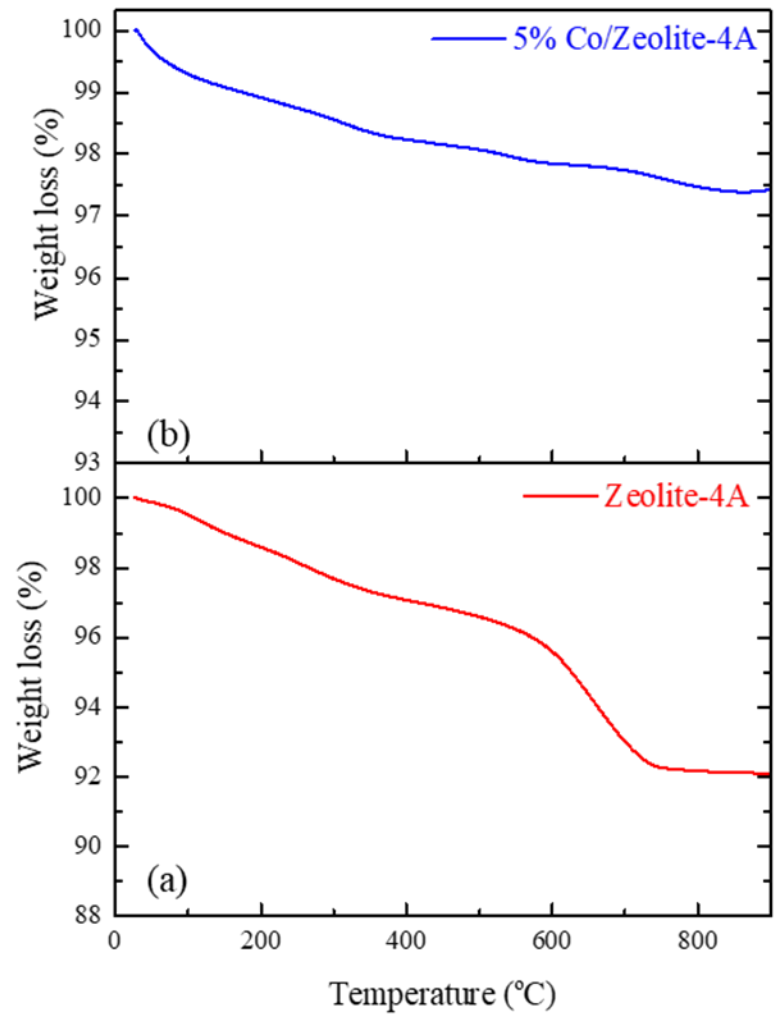

Figure 7. TGA analysis of fresh (a) Zeolite-4A before calcination (b) $\mathrm{Co} /$ Zeolite-4A after calcination. 
Figure 7(a-b) shows the thermogravimetric analysis results of Zeolite-4A and Co/Zeolite4A. As can be seen in the graph, the Zeolite-4A initially loses its moisture, $\sim 3 \%$, till $200{ }^{\circ} \mathrm{C}$, the second weight loss between $200-600{ }^{\circ} \mathrm{C}$ can be attributed to the desorption of volatiles within the zeolite lattice and the third weight loss in the region of $600-750{ }^{\circ} \mathrm{C}$ can be attributed to the formation of stable and pure Zeolite-4A [36]. The TGA analysis shows the calcined $\mathrm{Co} /$ Zeolite-4A is highly stable at high temperatures. The weight loss of $\sim 2.5 \%$ can be attributed to moisture loss absorbed and adsorbed in the Zeolite-4A framework. Once all the moisture is removed, no more weight loss is observed.

\subsection{Catalyst Screening and Stability Analysis for POM}

Figure 8 shows the results of catalytic screening test of Zeolite-4A, 2.5\% Co/Zeolite4A, 5\% Co/Zeolite-4A, 7.5\% Co/Zeolite-4A, and
10\% Co/Zeolite-4A. As can be seen in Figure 8 (a), Zeolite-4A itself possesses moderate activity for POM as average $\mathrm{CH}_{4}$ conversion is $\sim 30 \%$ with $\mathrm{H}_{2}$ and $\mathrm{CO}$ selectivity of $\sim 28 \%$ and $\sim 24 \%$, respectively. However, as soon as the Zeolite$4 \mathrm{~A}$ is impregnated with $\mathrm{Co}$, the average $\mathrm{CH}_{4}$ conversion increases significantly and achieves a maximum of $\sim 68 \%$ for $10 \% \mathrm{Co} /$ Zeolite- $4 \mathrm{~A}$. Figure 8 (b,c) show that the average $\mathrm{H}_{2}$ and $\mathrm{CO}$ selectivity follow a similar trend and reach $\sim 56 \%$ and $\sim 52 \%$, respectively. Figure 8 (d) shows that the $\mathrm{H}_{2}$ to $\mathrm{CO}$ ratio also stays $>1$ for all the compositions, indicating that $\mathrm{Co} /$ Zeolite$4 \mathrm{~A}$ catalysts are very practical for industrial applications.

The catalyst stability test carried out for $10 \% \mathrm{Co} /$ Zeolite-4A is presented in Figure 9. The catalyst was operated continuously for 24 h. The $\mathrm{CH}_{4}$ conversion initially increases for 5 h. and stabilizes. The $\mathrm{CH}_{4}$ conversion results than start declining gradually after $11 \mathrm{~h}$ and follows the declining trend until the end of the run. The $\mathrm{H}_{2}$ and $\mathrm{CO}$ selectivity results follow a
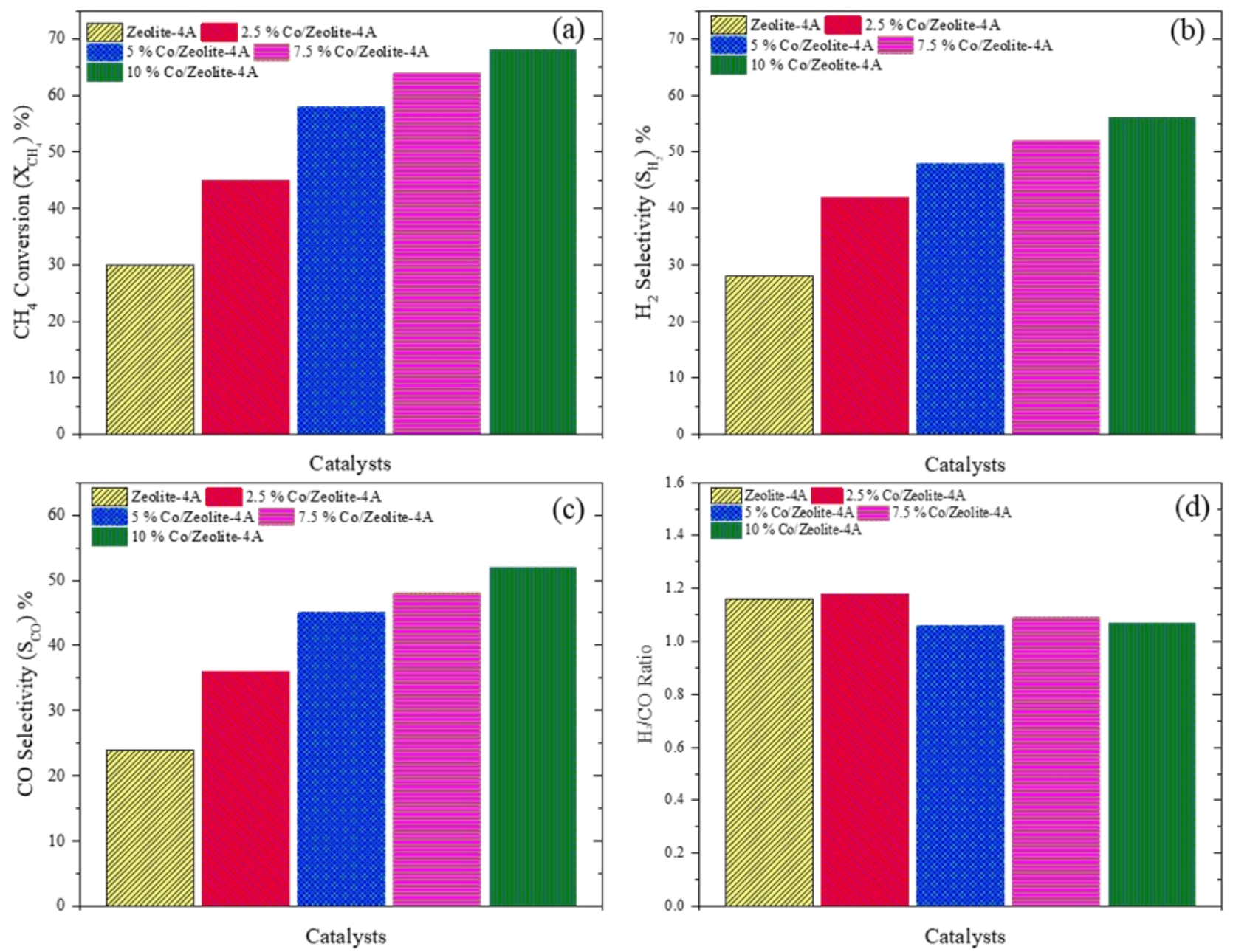

Figure 8. Catalyst screening (a) $\mathrm{CH}_{4}$ conversion (b) $\mathrm{H}_{2}$ selectivity (c) $\mathrm{CO}$ selectivity (d) $\mathrm{H}_{2} / \mathrm{Co}$ ratio; flow rate $30 \mathrm{~mL} \cdot \mathrm{min}^{-1}$, cat loading $0.25 \mathrm{~g}$, reaction temperature $800{ }^{\circ} \mathrm{C}, \mathrm{CH}_{4} / \mathrm{O}_{2}=2$. 
similar trend. Moreover, The $\mathrm{H}_{2}$ to $\mathrm{CO}$ ratio stays almost the same for $24 \mathrm{~h}$ and stays $>1$. The decrease in catalytic performance can be attributed to the formation of hot spots which result in the structural collapse and aggregation of the active phase $[38,39]$.

\subsection{Characterization of Spent Catalyst}

Spent catalyst of $10 \mathrm{wt} \%$ Co/Zeolite- $4 \mathrm{~A}$ was analyzed using SEM and TGA. The analysis shows the change in surface morphologies and crystal structure. Figure 10 (a) depicts the weight loss trend of the spent catalyst. Two major weight losses can be seen in the graph. The first major weight loss is attributed to the oxidation volatile organics formed during the

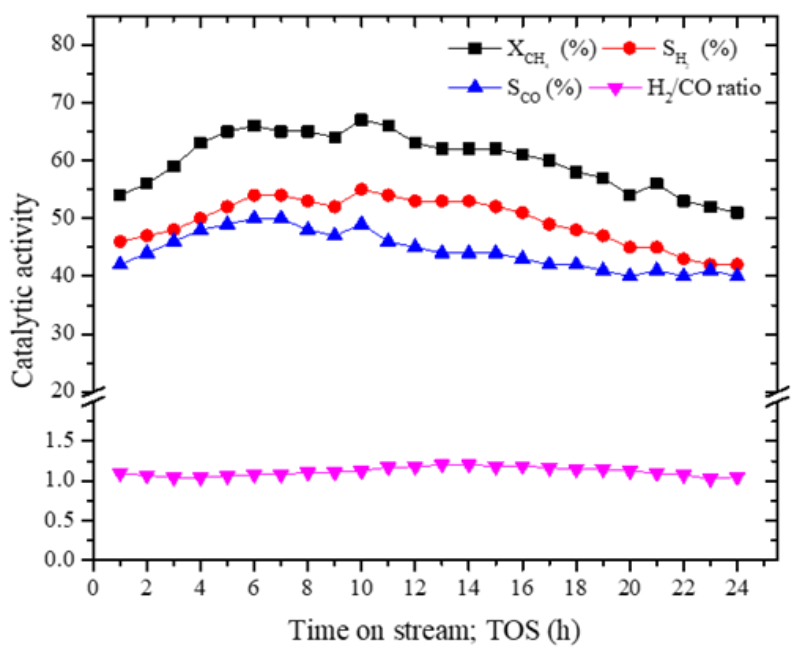

Figure 9. Effect of time on stream (TOS) on catalytic performance of $10 \mathrm{wt} \%$ Co/Zeolite- $4 \mathrm{~A}$.
POM reaction and deposited on the surface of the catalyst, while the second weight loss, after $700{ }^{\circ} \mathrm{C}$, can be attributed to the oxidation of graphitic carbon [4]. Figure 10 (b) presented the SEM micrograph obtained for the spent catalyst. The SEM image reveals that the surface morphology has changed considerably as majority of the surface is covered with deposited carbon. The deposited carbon can be seen to have granular structure. The coke formation can occur in catalytic partial oxidation of $\mathrm{CH}_{4}$ due to the formation of hot spots on the catalytic surface due to the fact that Zeolite-4A has insulating properties and is unable to dissipate heat properly [40]. The catalytic stability test also see a decline in performance and are supported by the SEM images.

\section{Conclusions}

Cobalt loaded Zeolite-4A with different Co loadings were examined as catalyst for the $\mathrm{POM}$ with $\mathrm{CH}_{4}$ to $\mathrm{O}_{2}$ ratio $=2$. The TGA of the prepared catalyst showed appreciable stability possessed by Co/Zeolite-4A. The SEM images showed that cobalt was successfully impregnated onto the Zeolite-4A framework. The catalytic activity test showed that Co/Zeolite- $4 \mathrm{~A}$ possess good catalytic activity for the POM achieving a maximum of $\sim 68 \%$ average $\mathrm{CH}_{4}$ conversion and a maximum of $\mathrm{H}_{2}$ and $\mathrm{CO}$ selectivity average of $\sim 56 \%$ and $\sim 52 \%$, respectively. The TOS test revealed that the catalyst possesses a good catalytic stability as $\mathrm{CH}_{4}$ conversion of $>50 \%$ can be seen even after $24 \mathrm{~h}$. of continuous operation. Therefore, it can be concluded that Zeolite-4A framework can be used as po-
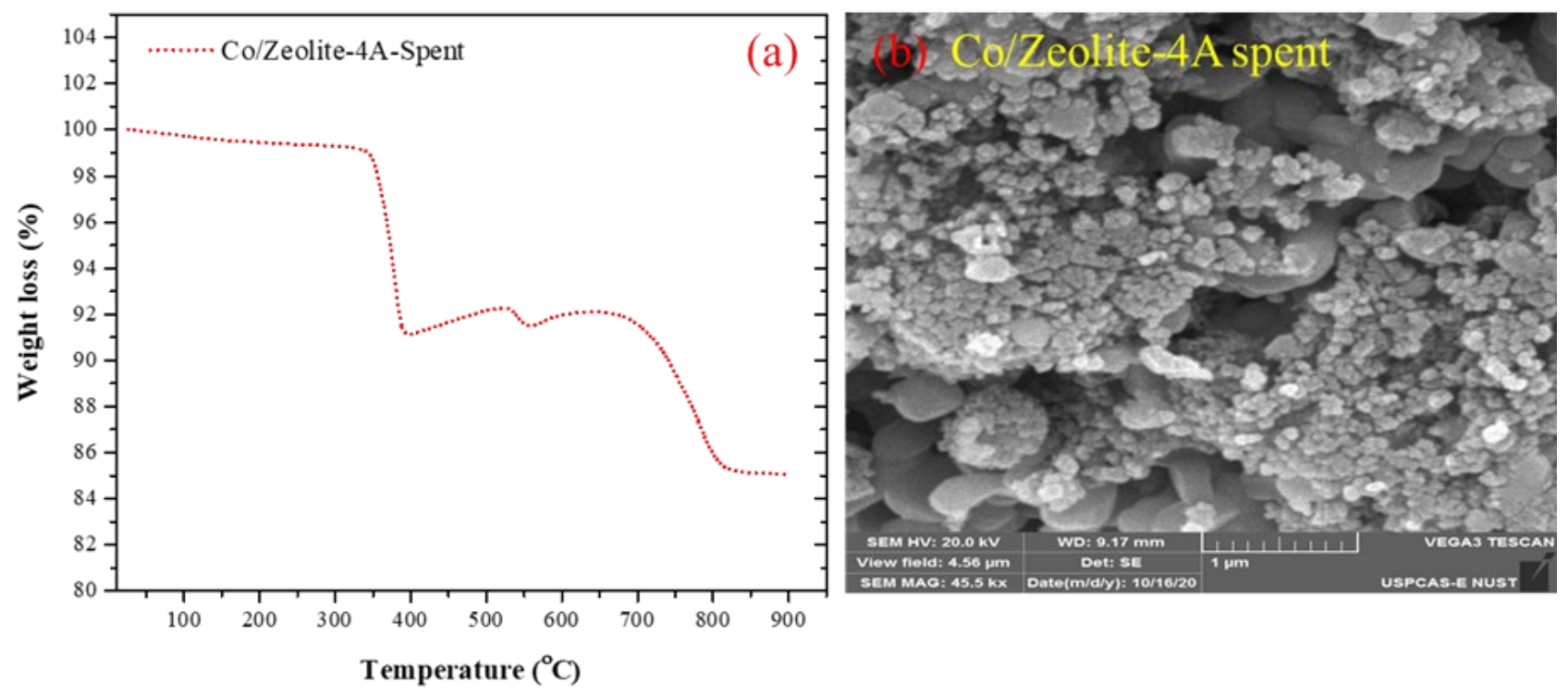

Figure 10. (a) TGA analysis of spent Co/Zeolite-4A (b) SEM analysis of spent Co/Zeolite-4A. 
tential catalyst support for industrial applications specially in reforming techniques for $\mathrm{H}_{2}$ production.

\section{Acknowledgement}

The authors are thankful to the USPCAS-E and SCME NUST for lab facilities.

\section{References}

[1] Khoja, A.H., Tahir, M., Amin, N.A.S. (2019). Process optimization of DBD plasma dry reforming of methane over $\mathrm{Ni} / \mathrm{La}_{2} \mathrm{O}_{3}-\mathrm{MgAl}_{2} \mathrm{O}_{4}$ using multiple response surface methodology. International Journal of Hydrogen Energy, $44(23), \quad 11774-11787$. D O I : 10.1016/j.ijhydene.2019.03.059

[2] Li, G., Cheng, H., Zhao, H., Lu, X., Xu, Q., Wu, C. (2017). Hydrogen production by $\mathrm{CO}_{2}$ reforming of $\mathrm{CH}_{4}$ in coke oven gas over $\mathrm{Ni}-\mathrm{Co} / \mathrm{MgAl}_{2} \mathrm{O}_{4}$ catalysts. Catalysis Today, 318, 46-51. DOI: 10.1016/j.cattod.2017.12.033

[3] Dedov, A.G., Loktev, A.S., Mukhin, I.E., Karavaev, A.A., Tyumenova, S.I., Baranchikov, A.E., Ivanov, V.K., Maslakov, K.I., Bykov, M.A., Moiseev, I.I. (2018). Synthesis Gas Production by Partial Oxidation of Methane and Dry Reforming of Methane in the Presence of Novel Ni-Co/MFI Catalysts. Petroleum Chemistry, 58(3), 203-213. DOI: 10.1134/S0965544118030052

[4] Fakeeha, A., Ibrahim, A.A., Aljuraywi, H., Alqahtani, Y., Alkhodair, A., Alswaidan, S., Abasaeed, A.E., Kasim, S.O., Mahmud, S., AlFatesh, A.S. (2020). Hydrogen Production by Partial Oxidation Reforming of Methane over Ni Catalysts Supported on High and Low Surface Area Alumina and Zirconia. Processes, 8(5), 499. DOI: 10.3390/pr8050499

[5] Fonseca, H.C., Bion, N., Epron, F., Ruiz, D., Marchetti, S.G., Bengoa, J.F., do Carmo Rangel, M. (2020). Partial oxidation of methane over lanthana-supported catalysts derived from perovskites. Catalysis Today, 344, 212-226. DOI: 10.1016/j.cattod.2019.02.010

[6] Khoja, A.H., Tahir, M., Amin, N.A.S. (2019). Evaluating the Performance of a Ni Catalyst Supported on $\mathrm{La}_{2} \mathrm{O}_{3}-\mathrm{MgAl}_{2} \mathrm{O}_{4}$ for Dry Reforming of Methane in a Packed Bed Dielectric Barrier Discharge Plasma Reactor. Energy \& Fuels, 33(11), 11630-11647. DOI: $10.1021 /$ acs.energyfuels.9b02236

[7] He, S., Castello, D., Krishnamurthy, K.R., AlFatesh, A.S., Winkelman, J.G.M., Seshan, K., Heeres, H.J. (2019). Kinetics of long chain nparaffin dehydrogenation over a commercial $\mathrm{Pt}-\mathrm{Sn}-\mathrm{K}-\mathrm{Mg} / \mathrm{Y}-\mathrm{Al}_{2} \mathrm{O}_{3}$ catalyst: Model studies using n-dodecane. Applied Catalysis A: General, $579, \quad 130-140$. D O I : 10.1016/j.apcata.2019.04.026
[8] Gillessen, B., Heinrichs, H., Hake, J.F., Allelein, H.J. (2019). Natural gas as a bridge to sustainability: Infrastructure expansion regarding energy security and system transition. Applied Energy, 251, 113377. DOI: 10.1016/j.apenergy.2019.113377

[9] Kaddeche, D., Djaidja, A., Barama, A. (2017). Partial oxidation of methane on coprecipitated $\mathrm{Ni}-\mathrm{Mg} / \mathrm{Al}$ catalysts modified with copper or iron. International Journal of Hydrogen Energy, 42(22), 15002-15009. DOI: 10.1016/j.ijhydene.2017.04.281

[10] Pruksawan, S., Kitiyanan, B., Ziff, R.M. (2016). Partial oxidation of methane on a nickel catalyst: Kinetic Monte-Carlo simulation study. Chemical Engineering Science, 147, 128-136. DOI: 10.1016/j.ces.2016.03.012

[11] Pantaleo, G., La Parola, V., Deganello, F., Singha, R.K., Bal, R., Venezia, A.M. (2016). $\mathrm{Ni} / \mathrm{CeO}_{2}$ catalysts for methane partial oxidation: Synthesis driven structural and catalytic effects. Applied Catalysis B: Environmental, $189, \quad 233-241$. D O I : 10.1016/j.apcatb.2016.02.064

[12] Gao, H., Zhou, L., Luo, X., Liang, Z. (2018). Optimized process configuration for $\mathrm{CO}_{2}$ recovery from crude synthesis gas via a rectisol wash process. Journal of Greenhouse Gas Control, 79, 83-90. D O I : 10.1016/j.ijggc.2018.10.005

[13] Zhang, L., Zhang, Q., Liu, Y., Zhang, Y. (2016). Dry reforming of methane over $\mathrm{Ni} / \mathrm{MgO}-\mathrm{Al}_{2} \mathrm{O}_{3}$ catalysts prepared by two-step hydrothermal method. Applied Surface Science, $389, \quad 25-33$. D O I : 10.1016/j.apsusc.2016.07.063

[14] Al-Fatesh, A.S., Abu-Dahrieh, J.K., Atia, H., Armbruster, U., Ibrahim, A.A., Khan, W.U., Fakeeha, A.H. (2019). Effect of pre-treatment and calcination temperature on $\mathrm{Al}_{2} \mathrm{O}_{3}-\mathrm{ZrO}_{2}$ supported Ni-Co catalysts for dry reforming of methane. International Journal of Hydrogen Energy, 44(39), 21546-21558. DOI: 10.1016/j.ijhydene.2019.06.085

[15] Yang, W., Fan, A., Yao, H., Liu, W. (2016). Effect of reduced pressures on the combustion efficiency of lean $\mathrm{H}_{2}$ /air flames in a micro cavity-combustor. International Journal of $\mathrm{Hy}$ drogen Energy, 41(34), 15354-15361. DOI: 10.1016/j.ijhydene.2016.06.208

[16] Khoja, A.H., Tahir, M., Amin, N.A.S. (2019). Recent developments in non-thermal catalytic DBD plasma reactor for dry reforming of methane. Energy Conversion and Management,

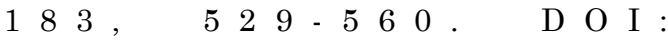
10.1016/j.enconman.2018.12.112 
[17] Iulianelli, A., Liguori, S., Wilcox, J., Basile, A. (2016). Advances on methane steam reforming to produce hydrogen through membrane reactors technology: A review. Catalysis Revi ews, $58(1), \quad 1-35$. D O I : $10.1080 / 01614940.2015 .1099882$

[18] Abdulrasheed, A., Jalil, A.A., Gambo, Y., Ibrahim, M., Hambali, H.U., Hamid, M.Y.S. (2019). Reviews, A review on catalyst development for dry reforming of methane to syngas: Recent advances. Renewable and Sustainable Energy Reviews, 108, 175-193. DOI: 10.1016/j.rser.2019.03.054

[19] Chein, R.Y., Fung, W.Y. (2019). Syngas production via dry reforming of methane over $\mathrm{CeO}_{2}$ modified $\mathrm{Ni} / \mathrm{Al}_{2} \mathrm{O}_{3}$ catalysts. International Journal of Hydrogen Energy, 44 (28), $\begin{array}{llllllllllllllll}1 & 4 & 3 & 0 & 3 & - & 1 & 4 & 3 & 1 & 5 & & & \text { D } & \mathrm{O} & \mathrm{I}\end{array}$ 10.1016/j.ijhydene.2019.01.113.

[20] Khoja, A.H., Anwar, M., Shakir, S., Mehran, M.T., Mazhar, A., Javed, A., Amin, N.A.S. (2020). Thermal dry reforming of methane over $\mathrm{La}_{2} \mathrm{O}_{3}$ co-supported $\mathrm{Ni} / \mathrm{MgAl}_{2} \mathrm{O}_{4}$ catalyst for hydrogen-rich syngas production. Research on Chemical Intermediates, 46, 3817-3833. DOI: $10.1007 / \mathrm{s} 11164-020-04174-\mathrm{z}$

[21] Yasuda, S., Osuga, R., Kunitake, Y., Kato, K., Fukuoka, A., Kobayashi, H., Gao, M., Hasegawa, J.-y., Manabe, R., Shima, H., Tsutsuminai, S., Yokoi, T. (2020). Zeolite-supported ultra-small nickel as catalyst for selective oxidation of methane to syngas. Communications Chemistry, 3, 129. DOI: 10.1038/s42004-02000375-0

[22] Melchiori, T., Di Felice, L., Mota, N., Navarro, R. M., Fierro, J. L. G., van Sint Annaland, M., Gallucci, F. (2014). Methane partial oxidation over a $\mathrm{LaCr}_{0.85} \mathrm{Ru}_{0.15} \mathrm{O}_{3}$ catalyst: Characterization, activity tests and kinetic modeling. $A p$ plied Catalysis A: General, 486, 239-249. DOI: 10.1016/j.apcata.2014.08.040

[23] Costa, D.S., Gomes, R.S., Rodella, C.B., da Silva Junior, R.B., Fréty, R., Neto, É.T., Brandão, S.T. (2020). Study of nickel, lanthanum and niobium-based catalysts applied in the partial oxidation of methane. Catalysis Today, $\quad 344, \quad 15-23$. D O I : 10.1016/j.cattod.2018.10.022

[24] Alvarez-Galvan, C., Melian, M., Ruiz-Matas, L., Eslava, J.L., Navarro, R.M., Ahmadi, M., Roldan, C.B., Fierro, J.L.G. (2019). Partial oxidation of methane to syngas over nickelbased catalysts: influence of support type, addition of rhodium, and preparation method. Frontiers in Chemistry, 7, 104. DOI: 10.3389/fchem.2019.00104
[25] Wang, F., Li, W.Z., Lin, J.D., Chen, Z.Q., Wang, Y. (2018). Crucial support effect on the durability of $\mathrm{Pt} / \mathrm{MgAl}_{2} \mathrm{O}_{4}$ for partial oxidation of methane to syngas. Applied Catalysis B: Environmental, 231, 292-298. DOI: 10.1016/j.apcatb.2018.03.018

[26] Choya, A., de Rivas, B., González-Velasco, J.R., Gutiérrez-Ortiz, J.I., López-Fonseca, R. (2020). Oxidation of lean methane over cobalt catalysts supported on Ceria/Alumina, $A p$ plied Catalysis A: General, 591, 117381. DOI: 10.1016/j.apcata.2019.117381

[27] Hou, Y., Ogasawara, S., Fukuoka, A., Kobayashi, H. (2017). Technology, Zeolitesupported rhodium sub-nano cluster catalyst for low-temperature selective oxidation of methane to syngas. Catalysis Science \& Technol-

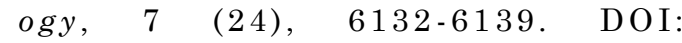
10.1039/C7CY02183F

[28] Hou, Y., Nagamatsu, S., Asakura, K., Fukuoka, A., Kobayashi, H. (2018). Trace monoatomically dispersed rhodium on zeolitesupported cobalt catalyst for the efficient methane oxidation. Communications Chemistry, 1(1), 1-7. DOI: 10.1038/s42004-018-0044-9

[29] Chen, J., Arandiyan, H., Gao, X., Li, J. (2015). Recent Advances in Catalysts for Methane Combustion. Catalysis Surveys from Asia, 19, 140-171. DOI: 10.1007/s10563-0159191-5

[30] Zasada, F., Janas, J., Piskorz, W., Gorczyńska, M., Sojka, Z. (2017). Total Oxidation of Lean Methane over Cobalt Spinel Nanocubes Controlled by the Self-Adjusted Redox State of the Catalyst: Experimental and Theoretical Account for Interplay between the Langmuir-Hinshelwood and Mars-Van Krevelen Mechanisms. ACS Catalysis, 7, $2853-2867$. D O I : 10.1021/acscatal.6b03139

[31] Munawar, M.A., Khoja, A.H., Hassan, M., Liaquat, R., Naqvi, S.R., Mehran, M.T., Abdullah, A., Saleem, F. (2021). Biomass ash characterization, fusion analysis and its application in catalytic decomposition of methane. Fuel, $285, \quad 119107$. D O I : 10.1016/j.fuel.2020.119107

[32] Khoja, A.H., Tahir, M., Amin, N.A.S. (2018). Cold plasma dielectric barrier discharge reactor for dry reforming of methane over $\mathrm{Ni} / \gamma$ $\mathrm{Al}_{2} \mathrm{O}_{3}-\mathrm{MgO}$ nanocomposite. Fuel Processing Technology, 178, 166-179. DOI: 10.1016/j.fuproc.2018.05.030 
[33] Wang, Q., Peng, Y., Fu, J., Kyzas, G.Z., Billah, S.M.R., An, S. (2015). Synthesis, characterization, and catalytic evaluation of $\mathrm{Co}_{3} \mathrm{O}_{4} / \mathrm{Y}-\mathrm{Al}_{2} \mathrm{O}_{3}$ as methane combustion catalysts: Significance of Co species and the redox cycle. Applied Catalysis B: Environmental, $168-169, \quad 42-50$. D O I : 10.1016/j.apcatb.2014.12.016

[34] Grzybek, G., Ciura, K., Wójcik, S., Gryboś, J, Indyka, P., Inger, M., Antoniak-Jurak, K., Kowalik, P., Kotarba, A., Sojka, Z. (2017). On the selection of the best polymorph of $\mathrm{Al}_{2} \mathrm{O}_{3}$ carriers for supported cobalt nano-spinel catalysts for $\mathrm{N}_{2} \mathrm{O}$ abatement: an interplay between preferable surface spreading and damaging active phase-support interaction. $\mathrm{Ca}$ talysis Science \& Technology, 7, 5723-5732. DOI: $10.1039 / \mathrm{C} 7 \mathrm{CY} 01575 \mathrm{E}$

[35] Bieseki, L., Penha, F.G., Pergher, S.B.C. (2013). Zeolite A synthesis employing a brazilian coal ash as the silicon and aluminum source and its applications in adsorption and pigment formulation. Materials Research, 16(1), 38-43. DOI: 10.1590/S151614392012005000144

[36] Iqbal, A., Sattar, H., Haider, R., Munir, S. (2019). Synthesis and characterization of pure phase zeolite 4A from coal fly ash. Journal of Cleaner Production, 219, 258-267. DOI: 10.1016/j.jclepro.2019.02.066
[37] Jamil, U., Khoja, A.H., Liaquat, R., Naqvi, S.R., Wan Omar, W.N.N., Amin, N.A.S. (2020). Copper and calcium-based metal organic framework (MOF) catalyst for biodiesel production from waste cooking oil: A process optimization study. Energy Conversion and Management, 215, 112934. DOI: 10.1016/j.enconman.2020.112934

[38] Ma, Y., Ma, Y., Chen, Y., Ma, S., Li, Q., Hu, X., Wang, Z., Buckley, C.E., Dong, D. (2020). Highly stable nanofibrous $\mathrm{La}_{2} \mathrm{NiZrO}_{6}$ catalysts for fast methane partial oxidation. Fuel, 265, 116861. DOI: 10.1016/j.fuel.2019.116861

[39] Hu, Y.H., Ruckenstein, E. (2004). Catalytic Conversion of Methane to Synthesis Gas by Partial Oxidation and $\mathrm{CO}_{2}$ Reforming, $\mathrm{Ad}$ vances in Catalysis, 48, 297-345. DOI: 10.1016/j.apcata.2008.05.018

[40] Leroi, P., Madani, B., Pham-Huu, C., Ledoux, M.-J., Savin-Poncet, S., Bousquet, J.L. (2004). $\mathrm{Ni} / \mathrm{SiC}$ : a stable and active catalyst for catalytic partial oxidation of methane. Catalysis Today, $91-92, \quad 53-58$. D O I : 10.1016/j.cattod.2004.03.009

Selected and Revised Papers from International Conference on Sustainable Energy and Catalysis 2021 (ICSEC 2021) (https://engineering.utm.my/chemicalenergy/icsec2021/) (School of Chemical and Energy Engineering, Faculty of Engineering, Universiti Teknologi Malaysia, 16-17th February 2021) after Peer-reviewed by Scientific Committee of ICSEC 2021 and Peer-Reviewers of Bulletin of Chemical Reaction Engineering \& Catalysis.

Editors (Guest) in this ICSEC 2021 section are Nor Aishah Saidina Amin, Mohd Asmadi Mohammed Yussuf, Salman Raza Naqvi, while Editor in Chief is I. Istadi. 